\title{
Neurological complications after H1N1 influenza vaccination
}

\author{
Complicações neurológicas após vacinação para gripe H1N1
}

Sir, the report on "neurological complications after H1N1 influenza vaccination " is very interesting. Lessa et al. reported that "H1N1 vaccination can result in important neurological complications probably secondary to post-vaccination inflammation" "and "MRI detected abnormalities in all patients.". In fact, the neurological problem can be seen in H1N1 influenza and the MRI finding in the infected case is noted ${ }^{2}$. The "diffuse prolonged $\mathrm{T} 1$ and $\mathrm{T} 2$ signal" is the main observation and this is the similar finding to the present described finding in post H1N1 influenza vaccination neurological complications ${ }^{1}$. In the pharmacovigilance report, the myelin disorder, as detected by MRI finding ${ }^{1}$, is the common adverse effect reaction due to H1N1 influenza vaccination ${ }^{3}$. Conclusively, MRI can be the good investigation for determining neurological complication resulted by both influenza infection and vaccination.

Sim Sai Tin ${ }^{1}$, Viroj Wiwanitkit ${ }^{2}$

References

1. Lessa R, Castillo M, Azevedo R, Azevedo F, Azevedo H. Neurological
complications after H1N1 influenza vaccination: magnetic resonance
imaging findings. Arq Neuropsiquiatr. 2014;72(7):496-9. http://dx.doi.
org/10.1590/0004-282X20140064
2. Zeng H, Quinet S, Huang W, Gan Y, Han C, He Y, Wang Y. Clinical and
MRI features of neurological complications after influenza A (H1N1) infection in critically ill children. Pediatr Radiol. 2013;43(9):1182-9. http://dx.doi.org/10.1007/s00247-013-2682-5

3. Durrieu G, Caillet C, Lacroix I, Jacquet A, Faucher A, Quarest S et al. [National Campaign of Vaccination against the flu A (H1N1)v: National Follow-up of Pharmacovigilance]. Therapie. 2011;66(6):527-40. French. http://dx.doi.org/10.2515/therapie/2011075

${ }^{1}$ Medical Center, Shantou, China;

${ }^{2}$ Hainan Medical University, Haikou, Hainan Province, China.

Correspondence: Sim Sai Tin; Medical Center; Shantou, China; E-mail: simsaitin@gmail.com

Conflict of interest: There is no conflict of interest to declare.

Received 25 July 2014; Received in final form 08 August 2014; Accepted 28 August 2014. 